\title{
Assessing Factors Affecting Intention to Adopt AI and ML: The Case of the Jordanian Retail Industry
}

\author{
Mohammed I Alghamdi* \\ Department of Computer Science, Al-Baha University, Al-Baha \\ City, Kingdom of Saudi Arabia
}

\author{
*Corresponding author \\ Mohammed I Alghamdi, Department of Computer Science, Al-Baha \\ University, Al-Baha City, Kingdom of Saudi Arabia
}

Submitted: 21 Oct 2020; Accepted: 07 Nov 2020; Published: 10 Nov 2020

\begin{abstract}
Summary
Aim: The aim of this research is to evaluate the factors that affect the adoption intention of AI and ML in the context of Jordan's retail industry

Method: For this research paper, primary data was collected with the help of surveying different retail companies that are operational in Jordan with a sample of 400 participants. The survey questionnaire was based on a Likert scale where five points ranging from strongly agree to strongly disagree were provided to the participants. Structural Equation Modelling (SEM) used to analyses the impact and significance of the different factors on the adoption of AI and ML in Jordanian retail sector.
\end{abstract}

Results: It has been concluded from this research paper that communication, government regulations, market structure, and technological infrastructure are important factors that influence the adoption of AI and ML in the retail industry of Jordan. However, the results of this research have pointed out that managerial support and vendor relationship do not have a significant influence on the adoption of AI and $M L$.

Limitations: The scope of the research is restricted to the context of the retail industry only. This research has been carried out in the context of Jordan thus it cannot be applied on to other geographical backgrounds. Due to the time and scope limitations, there are restricted factors considered in the framework.

Keywords: Artificial Intelligence, AI, Adoption Intention, Factors, Jordan, Machine Learning, ML, Retail Industry

\section{Introduction}

The concept of artificial intelligence has revolutionized the entire industry which has also changed the way in which most of the companies operate. It has been argued in the study of Alarie, Niblett and Yoon that the advent of artificial intelligence has shaped the way in which companies operate [1]. However, the adoption of artificial intelligence is still a challenging factor for most of the companies in the business environment [2]. It is due to the reason that there are various barriers for the adoption of artificial intelligence which restricts the companies for the purpose of effectively implementing the artificial intelligence [3]. In contrast to this, either the companies are not aware of the benefits provided by artificial intelligence or they lack the resources for the purpose of adopting the concept of artificial intelligence. It has been stated in the study of Di Vaio that there are various companies which are not aware of the benefits associated with the adoption of artificial intelligence [4]. On the other hand, the machine learning is one of the major applications of artificial intelligence which provides the systems with the ability to improve and learn automatically from the experience which has been programmed explicitly [5]. In this manner, the machine learning emphasis over the development of computer programs which can use and access the data for the purpose of learning [6-8]. It provides immense benefit to the companies in terms of enhancing their operations and making them much more efficient.

In contrast to this, the lack of awareness or the lack of resources does not allow these companies in the retail sector of Jordan to adopt and benefit from these technologies. It has been argued in the study of that there has been lack of development in the retail industry of Jordan which does not allow the companies in the retail sector to adopt the technological advancements in the industry [9]. In this manner, the lack of adoption of these advancements is affecting the retail operations of the companies in an adverse manner. Therefore, the performance of these companies is affected which must be considered by the companies. Moreover, the adoption intention of the companies depends on several factors 
with respect to the artificial intelligence and machine learning which must be considered and determined for the purpose of ensuring the effective adoption and implementation of the technology [10]. Considering these issues, this study has focused on determining the factors of artificial intelligence and machine learning which affects the adoption intention of the retail companies operating in the retail sector of Jordan. In this manner, the results of this study are intended to benefit the retail sector of Jordan in terms of determining the factors which influence the adoption intention of artificial intelligence and machine learning in Jordan.

\section{Literature Review}

For the adoption of artificial intelligence and machine learning, it is essential for the companies that they are provided with the infrastructure which can support the adoption of technology [11]. It is due to the reason that if the technology is not supported by the infrastructure, there would be an ineffective implementation of the technology. It has been argued in the study of Moberg and Blomberg that technological infrastructure is the most essential factor for companies with respect to the adoption of technology [12]. In this manner, the effect of technology support infrastructure has been tested over the adoption intention of artificial intelligence and machine learning in the retail industry of Jordan. Therefore, the first hypothesis has been developed for the purpose of testing the effect of technology support infrastructure on the AI and ML in Jordan which is provided below:

\section{$\mathbf{H}_{1}$ : There is a significant effect of technology support infrastructure on the AI and ML in Jordan.}

On the other hand, government regulations and policies have also been a critical factor in the adoption of artificial intelligence and machine learning. It is due to the reason that companies need to comply with the policies and regulations of technology adoption [13]. It has been argued in the study of Chen that the policies and regulations of the government are the major factors which restrict the companies for the purpose of adopting the artificial intelligence and machine learning [14]. In this manner, it is essential for companies to consider the regulations and policies of the government. Therefore, the second hypothesis has been developed for the purpose of testing the effect of government regulations and policies on the adoption intention of artificial intelligence and machine learning in the retail sector of Jordan. This hypothesis has been provided below:

$\mathbf{H}_{2}$ : There is a significant effect of government regulations and policies on the adoption intention of artificial intelligence and machine learning in Jordan.

Moreover, the market structure is yet another factor which has been determined to have influence over the adoption intention of machine learning and artificial intelligence. It is due to the reason that the market structure defines the operations of the company which must be supported by artificial intelligence and machine learning [15]. It has been argued in the study of Chen that the market structure affects the adoption of artificial intelligence and machine learning [14]. In this manner, the effect of government regulations and policies over the adoption intention of artificial intelligence and machine learning in Jordan has been tested. Therefore, the third hypothesis of the study is presented below:

$\mathbf{H}_{3}$ : There is a significant effect of market structure over the adoption intention of artificial intelligence and machine learning in Jordan.

In addition to this, managerial support is yet another factor which can influence the adoption intention of artificial intelligence and machine learning. It is due to the reason that the adoption of new technology is resisted by the employees and top management due to the change in process and procedures [16]. It has also been stated in the study of Chen that managerial support is one of the most significant factors which affect the adoption of new technology [14]. In this manner, the fourth hypothesis has been developed for the purpose of testing the effect of managerial support on the adoption intention of artificial intelligence and machine learning in the retail industry of Jordan. This hypothesis has been provided below:

$\mathbf{H}_{4}$ : There is a significant influence of managerial support over the adoption intention of artificial intelligence and machine learning in Jordan.

Additionally, the vendor partnership is yet another factor which influences the adoption intention of artificial intelligence and machine learning. It is due to the reason that with the partnership of the vendor, it is essential to integrate all the functions with the vendors for the affective implication of technology. It has also been argued in the study of Moberg and Blomberg that the partnership of vendor is essential in terms of adopting the artificial intelligence and machine learning as the integration of vendor can restrict the company towards the technology adoption [12]. In this manner, the fifth hypothesis has been developed for the purpose of testing the effect of vendor partnership on the adoption intention of artificial intelligence and machine learning in Jordan. This hypothesis has been provided below:

\section{$\mathbf{H}_{5}$ : There is a significant effect of vendor partnership on the adoption intention of artificial intelligence and machine learning in Jordan.}

Similarly, the communication process is also an essential factor which restricts the adoption intention of artificial intelligence and machine learning. It is due to the reason that with the effective communication process, the company is able to integrate all the functions involved in the process. It has been argued in the study of Moberg and Blomberg that the lack of communication process in the company adversely affects the adoption of artificial intelligence [12]. In this manner, the effect of the communication process on the adoption intention of artificial intelligence and machine learning in Jordan. This hypothesis has been provided below: 
$\mathbf{H}_{6}$ : There is a significant effect of the communication process on the adoption intention of artificial intelligence and machine learning in Jordan.

Furthermore, the characteristics of the firm have also been determined as one of the most crucial factors which influence the adoption of artificial intelligence and machine learning. It is due to the reason that the characteristics of the company must support the adoption of new technology. It has also been stated in the study of Moberg and Blomberg that the characteristics of the firm restrict the adoption of new technology if the company is not able to change the way it operates [12]. Therefore, the seventh hypothesis has been developed for the purpose of testing the effect of characteristics of the firm on the adoption intentions of artificial intelligence and machine learning in Jordan. This hypothesis has been provided below:

$\mathbf{H}_{7}$ : There is a significant effect of characteristics of the firm on the adoption intentions of artificial intelligence and machine learning in Jordan.

\section{Conceptual Model}

The below Figure 1 depicts the conceptual model of the study which shows the variables those have been adopted for the purpose of determining the effect of factors influencing the adoption intention of artificial intelligence and machine learning with respect to the companies operating in the retail industry of Jordan. In this manner, it is evident from the below Figure 1 that the factors which affect the adoption intention of artificial intelligence and machine learning in the retail industry of Jordan include technology support infrastructure, government regulations and policies, market structure, managerial support, vendor partnership, communication process and firm characteristics [12, 14]. On the other hand, the adoption intention of artificial intelligence and machine learning in the retail industry of Jordan has been considered as the dependent variable of the study.

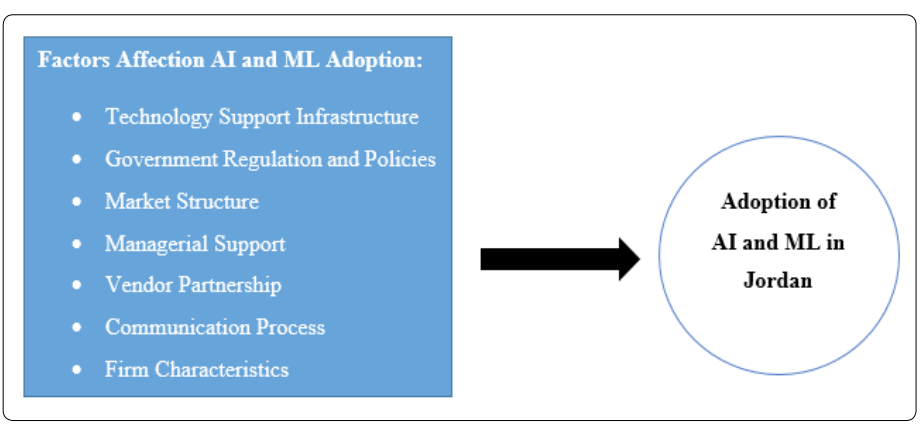

Figure 1: Conceptual Model of the Study

\section{Method and Materials}

This research paper follows a quantitative method where numeric information was used to collect and analyses data in order to achieve the aim and objectives of this research. For this research paper, primary data was collected with the help of surveying different retail companies that are operational in Jordan. The survey questionnaire was based on a Likert scale where five points ranging from strongly agree to strongly disagree were provided to the participants. The population of this research comprised of all the retail companies in Jordan however, suitable sample size was drawn in the light of the constraints of accessibility and time. With the help of a convenience sampling technique, a sample of 400 employees and managers from retail companies in Jordan. Structural Equation Modelling (SEM) has been used in this research paper in order to carry out a quantitative analysis of the data collected via a survey questionnaire. Confirmatory Factor Analysis (CFA) has been used to analyze the reliability of the constructs of the variables that are included in the research model. Path coefficients were used to analyze the impact and significance of the different factors on the adoption of AI and ML in Jordanian retail sector.

\section{Results}

For the purpose of assessing the reliability and validity of the different constructs of the variables included in the research framework, outer loadings, Cronbach Alpha, composite reliability, and average variance extracted have been used. The above metrics come under the broad category of confirmatory factor analysis. Table 1 indicates the results of the confirmatory factor analysis:

Table 1

Table 1: Confirmatory Factor Analysis

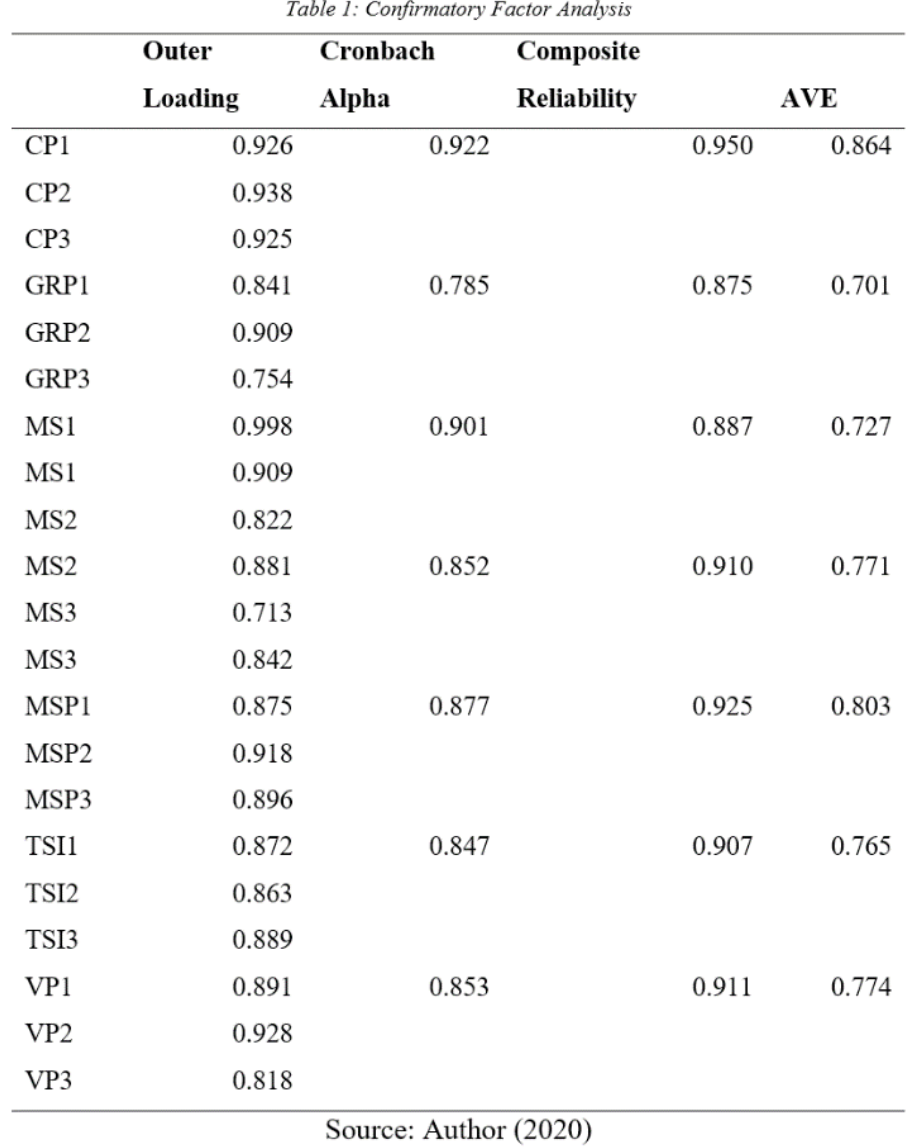

Outer loading shows the absolute contribution of an item with respect to its assigned construct. According to Hair, Ringle, and Sarstedt, outer loading needs to be higher than 0.70 in order for the 
constructs to reflect the variable sufficiently [17]. It is shown in table 1 that for all the variables, the constructs sufficiently define them. The next metric is of Cronbach alpha which for each variable represent the internal consistency of the scale used. The benchmark to test reliability via Cronbach alpha is 0.70 as per Ringle, Da Silva, Bido [18]. For this model, all the variables have been measured with the help of an internally consistent scale. The next metric for the purpose of determining reliability is composite reliability which also reflects the scale reliability when EFA is used for factor extraction. The acceptable range for composite reliability in CFA is 0.70 which is considered fair and 0.90 onwards is considered strong [19]. In the above table, nearly all variables have composite reliability greater than 0.90 thus, the internal consistency is very high. The last value given in table 1 is of average variance extracted (AVE) which indicate the variance in a construct that is caused due to fallacy in measurement. According to Hamid, Sami, and Sidek, the value of AVE should be greater than $50 \%$ or 0.50 to indicate that more than $50 \%$ of the variance is due to measurement error [20]. It is apparent in table 1 that based on AVE, all the variables are reliable.

The discriminant validity of the variables included in the research model is also important to be interpreted. It indicates that the measure of constructs that are supposed to be uncorrelated to one another are in fact not related to each other. Heterotrait-Monotrait Ratio (HTMT) is the metric through which discriminant validity has been determined for this research model:

Table 2

Table 2: Discriminant Validity

\begin{tabular}{llllll}
\hline Adoption & & & Manag & Marke & Technology \\
Intention & Commun & Government & erial & $\mathrm{t}$ & Support \\
associated with & ication & Regulation & Suppor & Struct & Infrastructur \\
ML and AI & Process & and Policies & $\mathrm{t}$ & ure & e \\
\hline
\end{tabular}

\begin{tabular}{|c|c|c|c|c|c|c|}
\hline \multicolumn{7}{|l|}{ Communicati } \\
\hline on Process & \multicolumn{6}{|l|}{0.785} \\
\hline \multicolumn{7}{|l|}{ Government } \\
\hline \multicolumn{7}{|l|}{ Regulation } \\
\hline and Policies & 0.862 & 0.598 & & & & \\
\hline \multicolumn{7}{|l|}{ Managerial } \\
\hline Support & 0.040 & 0.056 & 0.031 & & & \\
\hline \multicolumn{7}{|l|}{ Market } \\
\hline Structure & 0.837 & 0.688 & 0.861 & 0.036 & & \\
\hline \multicolumn{7}{|l|}{ Technology } \\
\hline \multicolumn{7}{|l|}{ Support } \\
\hline Infrastructure & 0.770 & 0.602 & 0.810 & 0.030 & 0.721 & \\
\hline \multicolumn{7}{|l|}{ Vendor } \\
\hline Partnership & 0.667 & 0.834 & 0.551 & 0.048 & 0.593 & 0.547 \\
\hline
\end{tabular}

Hensler, Ringle, and Sarstedt consider a value less than 0.90 to be suitable for HTMT as it shows that the correlation between the constructs is less than 0.90 [21]. Table 2 indicates that the value of HTMT for each variable is less than 0.90 hence the constructs that are not supposed to be related theoretically are in fact not correlated. After determining that the variables of the research model are statistically reliable and valid, the strength of the model can be determined with the help of R-square. The following table shows the results:

Table 3

Table 3: Quality Assessment

\begin{tabular}{crr}
\hline & \multicolumn{2}{c}{ R Square } \\
R Square & Adjusted \\
Adoption Intention associated with ML and AI & 0.713 & 0.708 \\
\hline Source: Author (2020) & &
\end{tabular}

The value of R-square shown in the above table indicates that the factors included in the research model tend to predict $71.3 \%$ of the variation in adoption intention associated with $\mathrm{ML}$ and AI. After adjusting the model for any discrepancies, the factors can predict $70.8 \%$ of the variations in the adoption of AI and ML by Jordanian retail firms. The R-squared can also be viewed from the following figure.

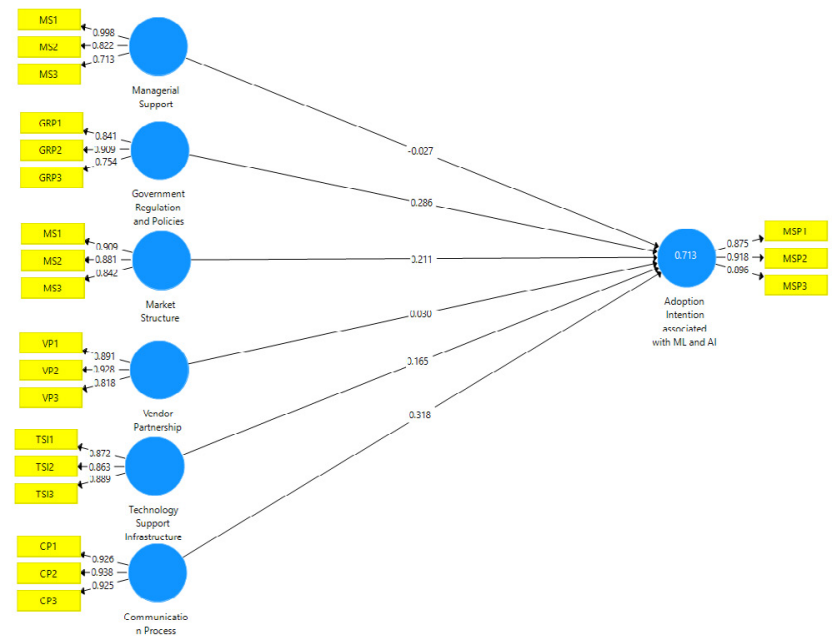

Figure 2: Measurement Model

Table 4

Table 4: Path Coefficients

\begin{tabular}{|c|c|c|c|c|}
\hline & $\begin{array}{l}\text { Original } \\
\text { Sample }\end{array}$ & $\begin{array}{l}\text { Standard } \\
\text { Deviation }\end{array}$ & $\begin{array}{l}\text { T } \\
\text { Statistics }\end{array}$ & $\begin{array}{l}P \\
\text { Values }\end{array}$ \\
\hline \multicolumn{5}{|c|}{ Communication Process -> Adoption Intention } \\
\hline associated with $\mathrm{ML}$ and $\mathrm{AI}$ & 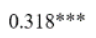 & 0.050 & 6.396 & 0.000 \\
\hline \multicolumn{5}{|c|}{ Government Regulation and Policies -> Adoption } \\
\hline Intention associated with $\mathrm{ML}$ and $\mathrm{AI}$ & $0.286^{* * *}$ & 0.053 & 5.354 & 0.000 \\
\hline \multicolumn{5}{|c|}{ Managerial Support $->$ Adoption Intention associated } \\
\hline with $\mathrm{ML}$ and $\mathrm{AI}$ & -0.027 & 0.029 & 0.920 & 0.358 \\
\hline \multicolumn{5}{|c|}{ Market Structure -> Adoption Intention associated with } \\
\hline $\mathrm{ML}$ and $\mathrm{AI}$ & $0.212 * * *$ & 0.052 & 4.096 & 0.000 \\
\hline \multicolumn{5}{|c|}{ Technology Support Infrastructure -> Adoption Intention } \\
\hline associated with $\mathrm{ML}$ and $\mathrm{AI}$ & $0.165^{\text {*** }}$ & 0.052 & 3.182 & 0.001 \\
\hline \multicolumn{5}{|c|}{ Vendor Partnership -> Adoption Intention associated } \\
\hline with $\mathrm{ML}$ and $\mathrm{AI}$ & 0.030 & 0.041 & 0.726 & 0.468 \\
\hline
\end{tabular}

Adv Mech Lear Art Inte, 2020

www.opastonline.com

Volume 1 | Issue 1 | 19 
The above table of path coefficients basically indicates the impact of the predictors or independent variable on the dependent construct. As this study is focused on the factors that promote adoption of AI and ML, hence the path coefficients show which of the factor has an impact over the adoption. The first factor in the model is the communication process which has a sig value of 0.000 which indicates significance hence the factor successfully results in the adoption of AI and ML. The second factor in the model is government regulations which have a sig value of 0.000 which indicates significance hence the factor successfully results in the adoption of AI and ML. The third factor in the model is managerial support which has a sig value of 0.358 which indicates no significance hence the factor does not play a role in the adoption of AI and ML. The fourth factor in the model is market structure which has a sig value of 0.000 which indicates significance hence the factor successfully results in the adoption of AI and ML. The fifth factor in the model is technology support which has a sig value of 0.001 which indicates significance hence the factor successfully results in the adoption of AI and ML. The last factor in the model is vendor partnership which has a sig value of 0.468 which indicates no significance hence the factor does not play a role in adoption of AI and ML.

Based on the results of this research, the following table shows the assessment of the hypotheses that were developed from the literature review:

\begin{tabular}{llll}
\hline S. No. & Hypotheses Statement & Sig Value & Result \\
\hline 1 & $\begin{array}{l}\text { Communication processes impact the adoption of AI and } \\
\text { ML in the retail industry of Jordan }\end{array}$ & Accepted \\
2 & $\begin{array}{l}\text { Government regulations impact the adoption of AI and } \\
\text { ML in the retail industry of Jordan }\end{array}$ & Accepted \\
3 & $\begin{array}{l}\text { Managerial support impacts the adoption of AI and ML } \\
\text { in the retail industry of Jordan }\end{array}$ & Rejected \\
4 & $\begin{array}{l}\text { Market Structure impacts the adoption of AI and ML in } \\
\text { the retail industry of Jordan }\end{array}$ & Accepted \\
Technology support infrastructure impacts the adoption & 0.001 & Accepted \\
of AI and ML in the retail industry of Jordan & & Rejected \\
Vendor relationship impacts the adoption of AI and ML & 0.468 & \\
in the retail industry of Jordan & &
\end{tabular}

\section{Discussion}

It has been determined from the above analysis that the communication process has significant influence over the adoption intention of artificial intelligence and machine learning in Jordan. It has also been supported in the study of Moberg \& Blomberg that the lack of communication process in the company adversely affects the adoption of artificial intelligence [12]. On the other hand, it is also determined that the significant influence of government policies and regulations on the adoption intention of artificial intelligence and machine learning in Jordan. It also aligns with the findings of Chen that the policies and regulations of the government are the most important factor which restricts the companies for the purpose of adopting the artificial intelligence and machine learning [14]. Moreover, the effect of market structure over the adoption intention of artificial intelligence and machine learning in Jordan. It also aligns with the study of Chen that the market structure affects the adoption of artificial intelligence and machine learning [14]. Lastly, the technology support infrastructure also has a significant influence on the adoption intention of artificial intelligence and machine learning in Jordan. It has also been argued in the study of Moberg and Blomberg that technological infrastructure is the most essential factor for companies with respect to the adoption of technology [12]. However, the effect of managerial support was not determined on the adoption intention of artificial intelligence and machine learning in Jordan. It contradicts with the study of Chen that managerial support is one of the most significant factors which affect the adoption of new technology [14].

\section{Limitations}

This research has been carried out in such a manner that the aim and objectives of the paper are being fulfilled, however, there are certain limitations which are to be acknowledged for the purpose of ensuring the reliability of the results. Firstly, the scope of the research is restricted to the context of the retail industry only. For each industry, there are different internal and external factors that can influence the adoption of AI and ML. Although some of the factors are common for all the industries such as managerial support and communication processes however, the results of this research cannot be necessarily applied to other industries. Moreover, this research has been carried out in the context of Jordan thus it cannot be applied on to other geographical backgrounds. Furthermore, due to the time and scope limitations, there are restricted factors considered in the framework. For future researches, other factors such as industry characteristics, relative advantage, and compatibility can be considered for the purpose of evaluating their role in influencing the adoption of AI and ML by retail companies.

\section{Conclusion}

This research has pointed out certain important factors that assist the retail companies in Jordan to adopt AI and ML. The factors in this research paper have been selected from the previous literature on the basis of which the survey questionnaire was designed to obtain first-hand information from the employees and managers working with the retail industry Jordan. The results that were obtained indicated that some of the factors do tend to impact the adoption while others were found not to be dependent on the adoption. It has been concluded from this research paper that communication, government regulations, market structure, and technological infrastructure are important factors that influence the adoption of AI and ML in the retail industry of Jordan. However, the results of this research have pointed out that managerial support and vendor relationship do not have a significant influence on the adoption of AI and ML. Although previous research has considered the aforementioned factors to be significant, however, in the context of the scope of this research and as per the results of primary findings, they are not found to be significant. 


\section{References}

1. Alarie B, NiblettA, Yoon AH (2018) How artificial intelligence will affect the practice of law. University of Toronto Law Journal, 68: 106-124.

2. Kruse L, Wunderlich N, Beck R (2019) Artificial Intelligence for the Financial Services Industry: What Challenges Organizations to Succeed. In Proceedings of the 52nd Hawaii International Conference on System Sciences 2019: 6408-6417.

3. Tambe P, Cappelli P, Yakubovich V (2019) Artificial intelligence in human resources management: Challenges and a path forward. California Management Review 61: 15-42.

4. Di Vaio A, Palladino R, Hassan R, Escobar O (2020) Artificial intelligence and business models in the sustainable development goals perspective: A systematic literature review. Journal of Business Research 121: 283-314.

5. Das S, Dey A, Pal A, Roy N (2015) Applications of artificial intelligence in machine learning: review and prospect. International Journal of Computer Applications 115: 31-41.

6. Dos Santos BS, Steiner MTA, Fenerich AT, Lima RHP (2019) Data mining and machine learning techniques applied to public health problems: A bibliometric analysis from 2009 to 2018. Computers \& Industrial Engineering 138: 106120.

7. Thrall JH, Li X, Li Q, Cruz C, Do S, et al. (2018) Artificial intelligence and machine learning in radiology: opportunities, challenges, pitfalls, and criteria for success. Journal of the American College of Radiology 15: 504-508.

8. Simard PY, Amershi S, Chickering DM, Pelton AE, Ghorashi, S, et al. (2017) Machine teaching: A new paradigm for building machine learning systems. arXiv preprint arXiv:1707.06742.

9. EL Samen AAA, Hiyasat R I (2017) Beyond the random location of shopping malls: A GIS perspective in Amman, Jordan. Journal of Retailing and Consumer Services 34: 3037.

10. Diez Olivan A, Del Ser J, Galar D, Sierra B (2019) Data fusion and machine learning for industrial prognosis: Trends and perspectives towards Industry 4.0. Information Fusion 50: 92111.

11. Brynjolfsson E, Rock D, Silverton C (2017) Artificial intelligence and the modern productivity paradox: A clash of expectations and statistics (No. w24001). National Bureau of Economic Research 2017: 1-44.

12. Moberg F, Blomberg E (2019) Artificial Intelligence Adoption-Is it more than just hype?

13. Bhatt B, Singh A (2020) Power Sector Reforms and Technology Adoption in the Indian Electricity Distribution Sector. Energy 2020: 118797.

14. Chen H (2019) Success Factors Impacting Artificial Intelligence Adoption---Perspective from the Telecom Industry in China.
15. Panch T, Szolovits P, Atun R (2018) Artificial intelligence, machine learning and health systems. Journal of global health, 8: 020303 .

16. Nejati M, Rabiei S, Jabbour CJC (2017) Envisioning the invisible: Understanding the synergy between green human resource management and green supply chain management in manufacturing firms in Iran in light of the moderating effect of employees' resistance to change. Journal of Cleaner Production 168: 163-172.

17. Hair JF, Ringle CM, Sarstedt M (2011) PLS-SEM: Indeed, a silver bullet. Journal of Marketing theory and Practice 19: 139-152.

18. Ringle C, Da Silva D, Bido D (2015) Structural Equation Modeling with the Smartpls. Brazilian Journal of Marketing, 13: $56-73$

19. Wong KKK (2013) Partial least squares structural equation modeling (PLS-SEM) techniques using SmartPLS. Marketing Bulletin 24: 1-32.

20. Ab Hamid MR, Sami W, Sidek MM (2017) September. Discriminant validity assessment: Use of Fornell \& Larcker criterion versus HTMT criterion. In Journal of Physics: Conference Seriesm, IOP Publishing 890: 012163.

21. Henseler J, Ringle CM, Sarstedt M (2015) A new criterion for assessing discriminant validity in variance-based structural equation modeling. Journal of the academy of marketing science 43: 115-135.

Copyright: (2020 Mohammed I Alghamdi. This is an open-access article distributed under the terms of the Creative Commons Attribution License, which permits unrestricted use, distribution, and reproduction in any medium, provided the original author and source are credited. 